\title{
Impact of Pharmacist-Given Patient-Counseling on Health-Related Quality of Life (HRQOL) of Haemodialysis Patients
}

\author{
Sobana Tamilselvan, Delphin Bencer William², Santhosh Jagadeesan³, Aneena Suresh ${ }^{4}$ \\ 1, 2,3,4 Department of Pharmacy Practice, JSS College of Pharmacy, JSS \\ Academy of Higher Education \& Research, Ooty, Nilgiris, Tamil Nadu, India.
}

\section{ABSTRACT}

\section{BACKGROUND}

End stage renal disease (ESRD) patients who are treated with haemodialysis experience many threats to their health-related quality of life (HRQOL), both from the large number of symptoms of disease itself and from the physical and mental burden of dialysis treatment. There are several scoring systems available to assess the quality of life of patients. Kidney disease quality of life (KDQOL-SFTM) scale is specifically designed for use in patients with kidney disease and who are on dialysis. Though, certain studies have utilised this scoring system, a pre-post counseling difference in quality of life was not measured. Hence, we assessed the impact of patient counseling on HRQOL of haemodialysis patients in a secondary care hospital using KDQOL-SFTM instrument.

\section{METHODS}

This is a prospective, longitudinal, pre-post interventional study. A total of 37 patients undergoing haemodialysis were identified and were randomly allocated into test and control groups. The HRQOL of each patient in both groups was measured at $1^{\text {st }}$ week and $4^{\text {th }}$ week using KDQOL-SFTM scale. The patients in the test group received patient counseling and additionally patient information leaflets were distributed after baseline quality of life (QOL) assessment. Paired t-test and unpaired t-tests were utilised to examine differences in QOL scores within and between the test and control groups.

\section{RESULTS}

Mean HRQOL scores were improved after patient counseling (P value $=0.0024)$ in the test group; difference in the QOL scores of test group compared to control group (P value $=0.0003$ ) was found to be significant.

\section{CONCLUSIONS}

Hence, it was found that pharmacist given patient counselling considerably improves the HRQOL of haemodialysis patients. Bed side counselling to haemodialysis patients by clinical pharmacist should be made part of the patient care offered in dialysis units.

\section{KEY WORDS}

End Stage Renal Disease, Haemodialysis, Health-Related Quality of Life, HRQOL, Patient Counseling, Pharmacist, Quality of Life
Corresponding Author: Dr. Aneena Suresh, Lecturer, Department of Pharmacy Practice, JSS College of Pharmacy, JSS Academy of Higher Education \& Research, Ooty - 643001,

Tamil Nadu, India.

E-mail: aneena@jssuni.edu.in

DOI: $10.14260 /$ jemds/2021/185

How to Cite This Article: Tamilselvan $S$, William DB, Jagadeesan $S$, et al. Impact of pharmacist-given patient counseling on health - related quality of life (hrqol) of haemodialysis patients. $J$ Evolution Med Dent Sci 2021;10(12):856860, DOI: $10.14260 /$ jemds $/ 2021 / 185$

Submission 23-10-2020,

Peer Review 23-01-2021,

Acceptance 02-02-2021,

Published 22-03-2021.

Copyright (c) 2021 Sobana Tamilselvan et al. This is an open access article distributed under Creative Commons Attribution License [Attribution 4.0 International (CC BY 4.0)] 


\section{BACKGROUND}

According to National Kidney Foundation, Chronic Kidney Disease (CKD) is defined as "Kidney damage for $\geq 3$ months, as defined by structural or functional abnormalities of the kidney, with or without decreased glomerular filtration rate (GFR)".1 The prevalence and incidence of end stage renal disease (ESRD) is rising worldwide, as a result of increasing rates of chronic diseases like hypertension and diabetes mellitus.2,3,4,5 According to National Kidney Foundation classification of chronic renal failure, the stage at which the GFR is less than 15 $\mathrm{ml} / \mathrm{min} / 1.73 \mathrm{~m}^{2}$ is called stage 5 or end stage renal disease (ESRD) where the treatment option is dialysis or transplantation. ${ }^{6}$ Over $65 \%$ of patients with ESRD require emergency hemodialysis.7,8 Haemodialysis is an expensive, time-consuming procedure done under fluid and dietary restrictions. Long term dialysis therapy will often result in disturbances in the family and social life, a loss of freedom, reduced or loss of financial income for the patients and dependence on caregivers. ${ }^{9}$ Due to these reasons, the physical, socioeconomic, psychological and environmental aspects of life in these patients are negatively affected, leading to compromised quality of life (QOL). ${ }^{10,11}$ Centres for Disease Control and Prevention (CDC) defines the health-related quality of life (HRQOL) as “an individual's or group's perceived physical and mental health over time". 12

Pharmacist can play an active role in delivering pharmaceutical care services to patients such as treatment chart review, identifying and resolving actual / potential drug related problems, counselling the patient on aspects of disease, drugs and lifestyle changes, which helps to improve the patient's condition and their quality of life by developing the confidence and getting rid of the myths regarding ESRD, improving the adherence to the treatment, decreasing and preventing the drug related problems (DRPs). ${ }^{13,14}$ "Pharmaceutical care focuses on the attitudes, commitments, functions, knowledge, responsibilities and skills of the pharmacist on providing the therapy with the goal of achieving definite therapeutic outcomes towards patient health and quality of life". ${ }^{15,16}$ Among these, patient counselling holds a significant role as it gives the pharmacist more time to spend with the patient, give disease-drug-diet-lifestyle related education which improves the patient's HRQOL to a great extent.

Therefore, we aimed to assess the impact of pharmacist given patient counselling on health-related quality of life (HRQOL) of haemodialysis patients in Nilgiris, Tamil Nadu, India.

\section{METHODS}

This is a prospective, longitudinal, pre-post interventional study was conducted in a dialysis unit of a secondary care hospital for a period of six months. Prior to data collection, the institutional review board approval was obtained (IEC / 10 / 2019 - 20). The Study was done from Oct 2019 to Oct 2020.

The sample size was calculated using the online sample size calculator called Calculator.net. Confidence interval was considered $95 \%$, margin of error $5 \%$, population proportion $50 \%$ and population size was 40 . The sample size hence obtained was 37 . We included 40 patients with ESRD undergoing haemodialysis who consented to participate in the study. Of this, 3 patients who voluntarily withdrew from dialysis or transferred to other hospitals, infected with human immunodeficiency virus (HIV) or hepatitis C, preparing for kidney transplantation and patients who died during the period of the study were excluded. Finally, 37 patients were included in our study. We used a sampling frame using the names of patients in the haemodialysis registry available in the haemodialysis unit of the hospital. Then each patient was given a unique identifier code. These patients were randomly allocated into two groups (test-receiving counselling and control not receiving counselling). Simple randomisation was done using randomiser.com.

The counselling was given to the patients in the test group at baseline $1^{\text {st }}$ week after calculating the quality of life scores. Each patient received $15-30$ minutes counselling and provided with patient information leaflets designed and validated. The patient's understanding of chronic kidney disease and haemodialysis was analysed by the pharmacist. Based on this, a counselling focusing on disease, diet, drugs and haemodialysis were given. The existing diet chart and the counselling in the haemodialysis unit of the hospital was very old. Upon request of the medical staff, this was revised. A brief description of chronic kidney disease and haemodialysis followed by diet including high protein, low sodium and potassium rich foods were advised. Patients were asked to restrict their fluid intake per day to $500-1000 \mathrm{ml}$ depending on the urine output. Safer antihypertensives and anti-diabetics in haemodialysis patients were explained. The health-related quality of life of each patient was measured at $1^{\text {st }}$ week and $4^{\text {th }}$ week using the kidney disease quality of life short form (KDQOL-SFTM) scale. ${ }^{17}$ The scoring was rated as $0-100$. Increased scores showed improved quality of life in the patients.

\section{Statistical Analysis}

Data was expressed as mean \pm standard deviation. Mean HRQOL within each group (group 1-test; group 2-control) at $1^{\text {st }}$ and $4^{\text {th }}$ week were compared using paired t-test. Difference in HRQOL of test and control group were compared using unpaired t-test. The P-value $<0.05$ was considered as statistically significant.

\section{RESULTS}

The demographic characteristics of the patients in both groups are shown in Table 1.

\begin{tabular}{|c|c|c|c|}
\hline & $\begin{array}{l}\text { Demographic } \\
\text { Characteristics }\end{array}$ & $\begin{array}{l}\text { Test Group } \\
\text { (Group 1) }\end{array}$ & $\begin{array}{c}\text { Control Group } \\
\text { (Group 2) }\end{array}$ \\
\hline & Total number of patients & 20 & 17 \\
\hline & Age & $\begin{array}{c}46.85 \pm \\
11.99243\end{array}$ & $\begin{array}{c}48.17647 \pm \\
11.3481\end{array}$ \\
\hline \multirow{2}{*}{ Gender } & Male & $14(70 \%)$ & $10(58.82 \%)$ \\
\hline & Female & $6(30 \%)$ & $7(41.176 \%)$ \\
\hline \multirow{3}{*}{ Frequency } & Once & $2(10 \%)$ & - \\
\hline & Twice & $15(75 \%)$ & $16(94.117 \%)$ \\
\hline & Thrice & $3(15 \%)$ & $1(5.88 \%)$ \\
\hline \multirow{3}{*}{ Comorbidities } & Hypertension & $12(60 \%)$ & $7(41.176 \%)$ \\
\hline & $\begin{array}{l}\text { Diabetes mellitus with } \\
\text { hypertension }\end{array}$ & $7(35 \%)$ & $10(58.82 \%)$ \\
\hline & Polycystic nephritis & $1(5 \%)$ & - \\
\hline \multicolumn{4}{|c|}{ Table 1. Patient Demographics } \\
\hline
\end{tabular}




\begin{tabular}{|c|c|c|c|}
\hline & Before Counselling & After Counselling & P Value \\
\hline Test group & $47.4371 \pm 12.66258$ & $987.566 \pm 11.85397$ & 0.0024 \\
\hline Control group & $50.9107 \pm 13.01211$ & $50.9107 \pm 13.01211$ & 0.0024 \\
\hline \multicolumn{4}{|c|}{ Table 2. Average HRQOL Scores of Test Group and Control Group } \\
\hline
\end{tabular}

From Table 2, it can be seen that there was a significant improvement in the overall mean quality of life scores at $4^{\text {th }}$ week in the test group patients $(\mathrm{P}$ value $=0.0024$; confidence interval $95 \%)$. We also found that there was a statistically significant deterioration in the mean QoL scores at $4^{\text {th }}$ week when compared with $1^{\text {st }}$ week in the control group $(\mathrm{P}$ value $=$ 0.0024; confidence interval $95 \%$ ).

\begin{tabular}{|c|c|c|c|}
\hline \multirow{2}{*}{ Scale (Items) } & \multicolumn{2}{|c|}{ Test Group } & \multirow{2}{*}{ P-Value } \\
\hline & $1^{\text {st }}$ Week & $4^{\text {th }}$ Week & \\
\hline Symptom / problems & 60.5975 & 62.5745 & 0.0763 \\
\hline Effects of kidney disease & 50.1 & 56.87275 & 0.0017 \\
\hline Burden of kidney disease & 42.1875 & 52.1875 & 0.0037 \\
\hline Work status & 40 & 37.5 & 0.32 \\
\hline Cognitive function & 48.4965 & 48.997 & 0.2194 \\
\hline Quality of social interaction & 70.58 & 70.9135 & 0.3299 \\
\hline Sleep & 40.995 & 41.245 & 0.32 \\
\hline Dialysis staff encouragement & 70.625 & 71.25 & 0.3299 \\
\hline Patient satisfaction & 44.1645 & 50.831 & 0.0165 \\
\hline Physical functioning & 36.75 & 36.5 & 0.8336 \\
\hline Role-physical & 21.25 & 25 & 0.1864 \\
\hline Pain & 41.375 & 40.5 & 0.3991 \\
\hline General health & 29.45 & 29.95 & 0.1625 \\
\hline Emotional well-being & 53.8 & 56.2 & 0.0358 \\
\hline Role-emotional & 51.663 & 53.3295 & 0.3299 \\
\hline Social function & 44.375 & 48.125 & ${ }^{*} 0.0102$ \\
\hline Energy / fatigue & 31 & 31.25 & 0.3299 \\
\hline \multicolumn{4}{|c|}{$\begin{array}{l}\text { Table 3. Mean HRQOL Scores on Domains of } \\
\text { KDQOL-SFTM (in Test Group) }\end{array}$} \\
\hline${ }^{*} \mathrm{P}$ value $<0.05$ is considered $\mathrm{s}$ & stically sign & & \\
\hline
\end{tabular}

Also, there was a substantial improvement in several items of KDQOL-SFTM questionnaire (effect of kidney disease, burden of kidney disease, patient satisfaction, emotional well-being and social functioning) as shown in Table 3.

\begin{tabular}{|cccc|}
\hline Patient No & Test Group & Control Group & P Value \\
\hline 1 & 2.88842 & -1.31789 & \\
2 & 0.76737 & -0.88158 \\
3 & 0 & -0.46278 \\
4 & 1.28527 & -0.35105 \\
5 & 0 & -0.32895 \\
\hline 6 & 0 & -0.04368 \\
\hline 7 & 5.75167 & 0.15211 \\
\hline 9 & 0 & -0.76222 \\
\hline 10 & 1.84211 & -0.27421 \\
\hline 11 & 1.56223 & -2.03889 \\
\hline 12 & 0.10948 & -1.45833 \\
\hline 13 & 6.57947 & -0.59211 \\
\hline 14 & 4.03972 & 0 \\
\hline 15 & 2.03222 & 0.36184 \\
\hline 16 & 0 & 0 \\
\hline 17 & 0.87737 & -2.08631 \\
\hline 18 & -0.74527 & -0.21053 \\
\hline 19 & 3.89263 & \\
\hline 20 & 0 & \\
\hline Table 4. Difference in HRQOL Scores of Test and Control Group \\
\hline$<0.05$ is considered statistically significant \\
\hline
\end{tabular}

Though it was not statistically significant, there was improvement in other items like symptom / problem list, cognitive function, quality of social interaction, sleep, dialysis staff encouragement, role physical, general health, role emotional etc. The difference of HRQOL (i.e., week 4 - week 1) of test group and control group were calculated. This was then compared using unpaired t-test which yielded a statistical significance $(\mathrm{P}$ value $=0.0003$; confidence interval of $95 \%$ ). This is depicted in Table 4.

\section{DISCUSSION}

Prospective evaluation of health-related quality of life of ESRD patients showed decreasing scores with advancing stages. ${ }^{18}$ Life in ESRD is miserable, food and fluid restrictions are mandatory for these patients due to hyperkalaemia, high blood pressure and fluid retention. Although people with ESRD are now able to live longer due to medical advancements, they often experience many physical changes which can negatively impact their quality of their life. The focus of healthcare for these patients has shifted from survival to achieving an acceptable QOL. Various types of interventions like patient education, group participation and psychiatric counseling have been developed as tools to achieve this goal.

Certain studies have shown that counselling about the kidney disease, life style modification (mainly on fluid and diet restrictions), treatment adherence, stress and emotional problems caused by kidney disease will help ESRD patients not to be worried about effects of kidney disease on their daily life. ${ }^{19-21}$ Extra care for the patients can also help to improve the relationship between the patients and healthcare provider which ultimately leads to increase in the patient satisfaction. ${ }^{22,23}$

In our study, several items of KDQOL-SFTM questionnaire like effect of kidney disease, burden of kidney disease, patient satisfaction, emotional well-being and social functioning showed significant improvement in test group after providing patient counselling $(\mathrm{P}<0.05)$. Similar results were evident in study conducted by UdayVenkat Mateti, et.al with significant improvement in domains like physical functioning, general health, emotional well-being, social functioning, symptom / problem list and effects of kidney disease with $\mathrm{P}<0.05 .22$ Shirinsadat Badri, et al. conducted a similar study with 120 patients and used SF-36 scale to measure health related quality of life. HRQOL improved significantly from 56.9 at the initiation of the study to 72.2 at the end of the study in the case group and especially there was significant improvement in the role emotional, mental health, social functioning and general health dimensions. ${ }^{20}$

Suja Abraham et.al, conducted a study with 50 patients and used World Health Organization (WHO) QOL scale to measure QOL and showed a significant improvement in psychological domain with $\mathrm{P}<0.001 .{ }^{19}$ Abraham et al. conducted a study with 81 patients using WHO QOL scale and showed a significant improvement in all the four domains physical, psychological, social and environmental $(\mathrm{P}<0.001)$. Javedh Shareef et al. conducted a study with 60 patients using WHO QOL scale among the four domains, improvement was seen in both psychological $(\mathrm{P}<0.01)$ and physical health $(\mathrm{P}<0.05)$ domain. ${ }^{7}$ 
Also, in our study a significant improvement in the mean HRQOL scores before and after patient counselling was observed in test group $(\mathrm{P}$ value $=0.0024)$. The study conducted by Seema Sharma et.al also revealed similar results with improvement in social functioning, emotional and mental parameters $(\mathrm{P}=0.01)$ indicating the impact of patient counseling. ${ }^{14}$

\section{CONCLUSIONS}

The results of our study demonstrate that patient counselling provided by the pharmacist plays an important role in improving the HRQOL. Patient counselling provided by the pharmacist should be implemented by incorporating clinical pharmacist in the nephrology team to make the haemodialysis patient understand his illness and treatment to create a positive environment which results in better quality of life.

\section{Limitations}

Though we could get significant results in QOL scores impacted by patient counselling, our study was limited by small sample size, short duration, and single centre. Pharmacist could have been involved in identifying and resolving drug related problems as well that would help to modify patient's pharmaceutical care plan, meet therapeutic goals that would ultimately lead to improving the quality of life of patient.

Data sharing statement provided by the authors is available with the full text of this article at jemds.com.

Financial or other competing interests: None.

Disclosure forms provided by the authors are available with the full text of this article at jemds.com.

The authors express their sincere gratitude to the medical and paramedical staff of dialysis unit, Government District Headquarters Hospital, Ooty, Tamil Nadu, India, for their provision of information and support for the completion of the study.

\section{REFERENCES}

[1] National Kidney Foundation. KDOQI clinical practice guidelines for chronic kidney disease: evaluation, classification and stratification. Am J Kidney Dis 2002;39(2 Suppl 1):S1-S266.

[2] Shareef J, Kripa GS, Baikunje S. Impact of Pharmacists' counseling on quality of life in patients undergoing hemodialysis in a tertiary care teaching hospital. World J Nephrol Urol 2014;3(4):143-50.

[3] Leonberg-Yoo, Amanda K, Weiner DE. Core concepts in dialysis and continuous therapies. In: Colm CM, Tucker JK, Singh AK, eds. Epidemiology of end-stage renal disease. $1^{\text {st }}$ edn. Boston, MA, US: Springer 2016:3-13.

[4] National Kidney Foundation. Guide to Understanding Kidney Disease 2020 [Cited 28 May 2020]. https://www.kidney.org/atoz/atozTopic_KidneyDisease

[5] Health N. What is chronic kidney disease? National Institute of Diabetes and Digestive and Kidney Diseases $2020 \quad$ [Cited 2 May 2020]. https://www.niddk.nih.gov/health-information/kidney- disease/chronic-kidney-disease-ckd/what-is-chronickidney-disease.

[6] National Kidney Foundation. Kidney Disease Quality Outcomes Initiative (K/DOQI) 2020. [Cited 28 May 2020]. http://www.kidney.org/professionals/kdoqi/guidelines. cfm.

[7] Abraham S, Ramachandran A. Estimation of quality of life in hemodialysis patients. Indian J Pharma Sci 2012;74(6):583-7.

[8] Varughese S, Abraham G. Chronic kidney disease in India: a clarion call for change. Clin J Am Soc Nephrol 2018;13(5):802-4.

[9] Mollaoğlu M. Quality of life in patients undergoing hemodialysis. IntechOpen 2013. https://www.intechopen.com/books/hemodialysis/qual ity-of-life-in-patients-undergoing-hemodialysis.

[10] Kliger AS, Finkelstein FO. Can we improve the quality of life for dialysis patients? Am J Kidney Dis 2009;54(6):9935.

[11] Jaar BG, Chang A, Plantinga L. Can we improve quality of life of patients on dialysis? Clin J Am Soc Nephrol 2013;8(1):1-4.

[12] HRQOL Concepts CDC. Cdc.gov. 2018 [cited 4 September 2020]. https://www.cdc.gov/hrqol/concept.htm.

[13] Cruz MC, Andrade C, Urrutia M, et al. Quality of life in patients with chronic kidney disease. Clinics (Sao Paulo) 2011;66(6):991-5.

[14] Sharma S, Rani RHS, Subramanyam G, et al. Evaluation of impact of counseling on quality of life of chronic kidney disease and hemodialysis patients. Indian J Pharm Pract 2013;6(3):57-61.

[15] The role of the pharmacist in the health care system: Part II: The role of the pharmacist: quality pharmaceutical services - benefits for governments and the public. pharmaceutical care. apps.who.int. 2020 [cited 30 March 2020]. https://apps.who.int/medicinedocs/en/d/Jh2995e/ 2.2.html.

[16] Mateti UV, Nagappa AN, Bairy M, et al. Pharmaceutical care for dialysis patients. Sys Rev Pharm 2013;4(1):1-6.

[17] Hays DR, Kallich J, Mapes D, et al. Kidney Disease Quality of Life Short Form (KDQOL-SF), Version 1.3: a manual for use and scoring. Rand 1997 [cited 2 May 2020]. https://www.rand.org/content/dam/rand/pubs/papers /2006/P7994.pdf.

[18] Md Yusop NB, Mun CY, Shariff ZM, et al. Factors associated with quality of life among hemodialysis patients in Malaysia. PLoS One 2013;8(12):e84152.

[19] Abraham S, Venu A, Ramachandran A, et al. Assessment of quality of life in patients on hemodialysis and the impact of counseling. Saudi J Kidney Dis Transpl 2012;23(5):9537.

[20] Dashti-Khavidaki S, Sharif Z, Khalili H, et al. The use of pharmaceutical care to improve health-related quality of life in hemodialysis patients in Iran. Int J Clin Pharm 2013;35(2):260-7.

[21] Thomas D, Joseph J, Francis B, et al. Effect of patient counseling on quality of life of hemodialysis patients in India. Pharm Pract (Granada) 2009;7(3):181-4.

[22] Alowayqilah KM, Alansari SA, Alquraini WS, et al. Impact of counseling in end stage renal disease patients of riyadh (KSA). Saudi J Med Pharm Sci 2016;2(9):236-40. 
[23] Mateti UV, Nagappa AN, Attur RP, et al. Impact of pharmaceutical care on the health-related quality of life among hemodialysis patients-a multicenter randomized controlled study. Saudi J Kidney Dis Transpl 2017;28(6):1293-306. 